\title{
DETERMINATION OF AFLATOXINS AND OCHRATOXIN A IN WHEAT FROM DIFFERENT REGIONS OF TURKEY BY HPLC WITH FLUORESCENCE DETECTION
}

\author{
S. TURKSOY* and B. KABAK \\ Department of Food Engineering, Faculty of Food Engineering, Hitit University, 19030, Corum, Turkey.
}

(Received: 2 October 2019; accepted: 9 December 2019)

\begin{abstract}
This study examines the occurrence of aflatoxins $\left(\mathrm{AF}_{\mathrm{S}}\right)$ and ochratoxin $\mathrm{A}(\mathrm{OTA})$ in bread and durum wheat samples. A total of 141 samples were collected from eleven different regions of Turkey. An analytical method based on liquid extraction, immunoaffinity column (IAC) clean-up followed by high performance liquid chromatography (HPLC) was used for the determination of AFs and OTA levels. As a result, AFs and OTA were detected in $2 \%$ and $9.2 \%$ of wheat samples at concentrations varying from 0.21 to $0.44 \mu \mathrm{g} \mathrm{kg}^{-1}$ and from 0.1 to $3.2 \mu \mathrm{g} \mathrm{kg}^{-1}$, respectively. Aflatoxin $\mathrm{B}_{1}\left(\mathrm{AFB}_{1}\right)$ and aflatoxin $\mathrm{B}_{2}\left(\mathrm{AFB}_{2}\right)$ were found positive in samples ranging between $0.21-0.35 \mu \mathrm{g} \mathrm{kg} \mathrm{and}^{-1}$ $0.094 \mu \mathrm{g} \mathrm{kg}^{-1}$, respectively. However, none of the samples contained aflatoxin $\mathrm{G}_{1}\left(\mathrm{AFG}_{1}\right)$ and aflatoxin $\mathrm{G}_{2}\left(\mathrm{AFG}_{2}\right)$. The study also recommended that contamination levels in wheat and wheat-based products should be routinely monitored in greater sample numbers to insure food safety.
\end{abstract}

Keywords: aflatoxin, ochratoxin A, HPLC, wheat

Wheat (Triticum aestivum L. em Thell.) has been considered as one of the most important and strategic cereal crops for the majority of the world's population. World wheat market data show that the mean global wheat production increased over the period 2013 to 2018, reaching a maximum of 740 million tons (FAO, 2018). In Turkey, wheat production values showed a sharp increase in demand, peaking at approximately 21.5 million tons in 2017 (TUIK, 2018). These values made Turkey one of the highest wheat-producing countries in the world. The daily average consumption of wheat-based products in Turkey is almost $50 \%$, two times higher than most modern, industrialized Western countries (GIRAY et al., 2007).

Foodstuffs produced from wheat (bread, pasta, semolina, bulgur, cookie, etc) are incredibly susceptible to mycotoxin contamination caused by a fungal infection during preharvest, harvest, and post-harvest handling conditions. Among mycotoxins, the most toxic, dangerous, and common mycotoxins are aflatoxins $\left(\mathrm{AF}_{\mathrm{S}}\right)$ and ochratoxin $\mathrm{A}(\mathrm{OTA}) . \mathrm{AF}_{\mathrm{S}}$ are produced by some Aspergillus species such as Aspergillus flavus and Aspergillus parasiticus, while Penicillium verrucosum and Aspergillus ochraceus are mainly responsible for OTA production (EFSA, 2006). Aflatoxin $\mathrm{B}_{1}\left(\mathrm{AFB}_{1}\right)$, aflatoxin $\mathrm{B}_{2}\left(\mathrm{AFB}_{2}\right)$, aflatoxin $\mathrm{G}_{1}\left(\mathrm{AFG}_{1}\right)$, and aflatoxin $\mathrm{G}_{2}\left(\mathrm{AFG}_{2}\right)$ among identified $\mathrm{AF}_{\mathrm{S}}$ can be found naturally in foods. Moreover, $\mathrm{AFB}_{1}$ shows the highest genotoxic and carcinogenic potential (listed as a group I by International Agency for Research on Cancer, IARC). Apart from $\mathrm{AF}_{\mathrm{s}}$, OTA presents a potent carcinogenic (group 2B) danger to all mammalian species (EFSA, 2006) and is discovered to be the major cause of a fatal human kidney disease referred to as Balkan Endemic Nephropathy and upper urinary tract cancer (IARC, 1993). Additionally, wheat contamination by both $\mathrm{AF}_{\mathrm{S}}$ and OTA is responsible for serious economic losses in both the industry and related manpower productivity.

* To whom correspondence should be addressed.

Phone: +90 364227 4533; fax: +90 364227 4535; e-mail: secilturksoy@hitit.edu.tr

0139-3006 C 2020 Akadémiai Kiadó, Budapest 
In order to bring this safety problem under control, certain limiting regulations for $\mathrm{AF}_{\mathrm{S}}$ and OTA contents in wheat have been implemented with varying maximum tolerance levels. The European Commission (EC, 2006b) sets maximum levels (MLs) of $2 \mu \mathrm{g} \mathrm{kg}^{-1}$ for $\mathrm{AFB}_{1}$ and $4 \mu \mathrm{g} \mathrm{kg}^{-1}$ for sum of $\mathrm{AF}_{\mathrm{S}}$ (total AFs) in all cereals and all products derived from wheat. The ML for unprocessed cereals is $5 \mu \mathrm{g} \mathrm{kg}^{-1}$ for OTA (EC, 2006b).

The contamination of wheat grains with AFs and OTA is a worldwide problem. The occurrence of AFs contamination in wheat samples was $22 \%\left(0.04-0.12 \mu \mathrm{g} \mathrm{kg}^{-1}\right)$ in China (Zhao et al., 2018), 30\% (0.01-6.9 $\mu \mathrm{g} \mathrm{kg}^{-1}$ ) in Iran (Namjoo et al., 2016), 35\% (0.01-2.0 $\mu \mathrm{g} \mathrm{kg}^{-1}$ ) in Lebanon (Joubrane et al., 2011), 54\% (102.9-198.4 $\mu \mathrm{g} \mathrm{kg}^{-1}$ ) in Nigeria (MaKun et al., 2010), and 20\% (1.8-15.5 $\mu \mathrm{g} \mathrm{kg}^{-1}$ ) in Pakistan (LutFullaH \& Hussain 2012). The incidence of OTA in wheat samples has been reported in many countries including Spain (30\%, 0.2-2.3 $\mu \mathrm{g} \mathrm{kg}^{-1}$ ) (VIDAL et al., 2013), Poland (18\%, 0.9-2.9 $\mu \mathrm{g} \mathrm{kg}^{-1}$ ) (HAJOK et al., 2019), Germany (21\%, 0.6-0.8 $\mathrm{gg} \mathrm{kg}^{-1}$ ) (BIRzele et al., 2000), Algeria (69\%, 0.2-27.3 $\mu \mathrm{g} \mathrm{kg}^{-1}$ ) (ZeBIRI et al., 2019), and India (58\%, 1.36-21.17 $\mu \mathrm{g} \mathrm{kg}^{-1}$ ) (Kumar et al., 2012). However, there is little data about $\mathrm{AF}_{\mathrm{S}}$ and OTA contamination levels for different wheat grains grown in Turkey. Therefore, the main purpose of this survey was to screen $\mathrm{AF}_{\mathrm{S}}$ and OTA contents of wheat samples grown in different locations of Turkey, using a validated analytical method (HPLC coupled with fluorescence detection).

\section{Materials and methods}

\subsection{Samples}

A total of 141 wheat samples harvested in 2017 were collected from different agricultural research institutes and Çorum Commodity Exchange located in 11 different provinces of Turkey (Fig. 1). During the harvest season of 2017, the sampling of the wheat grains was performed as described in Commission Regulation No 401/2006 (EC, 2006a). At least $2 \mathrm{~kg}$ of wheat samples were milled on a standard Buhler laboratory mill (Brabender, Germany) purging any impurities by sieving. Each whole wheat flour sample was collected in plastic bags and properly stored at $-18^{\circ} \mathrm{C}$ until extraction, and clean-up procedures were precisely and meticulously implemented.

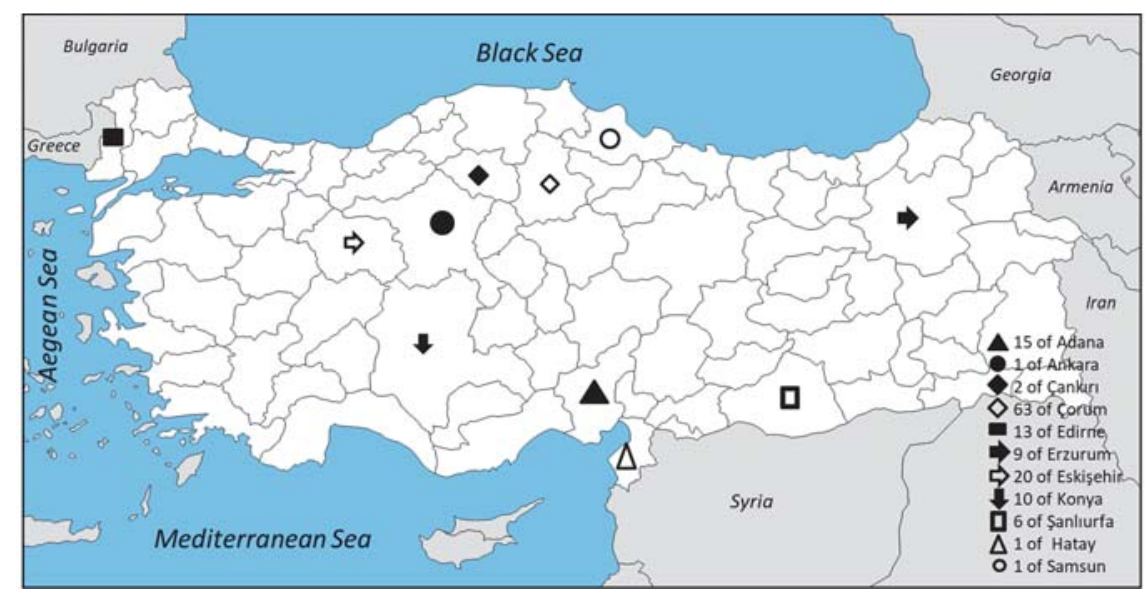

Fig. 1. Locations of wheat sampling points 


\subsection{Reagents and chemicals}

HPLC and analytical grade reagents were purchased from Sigma-Aldrich (St. Louis, MO, USA) and Merck (Darmstadt, Germany). Water was purified by a Milli Q purification system (Millipore, Molsheim, France). Immunoaffinity columns $\left(\mathrm{IAC}_{\mathrm{S}}\right)$, AflaTest ${ }^{\circledR}$ and OchraTest ${ }^{\mathbb{}}$ were from Vicam (Watertown, MA, USA).

Standard solution of $\mathrm{AF}_{\mathrm{S}}$ mixture $\left(\mathrm{AFB}_{1}+\mathrm{AFB}_{2}+\mathrm{AFG}_{1}+\mathrm{AFG}_{2}\right)$ at $2.6 \mu \mathrm{g} \mathrm{ml}^{-1}$ concentration in methanol and pure OTA standard $(1 \mathrm{mg})$ were supplied by Supelco ${ }^{\circledR}$ (Bellefonte, PA, USA) and Sigma-Aldrich (St. Louis, MO, USA), respectively.

\subsection{Extraction and IAC clean-up procedure}

AFs and OTA were extracted from wheat samples according to the method described previously by KARA and co-workers (2015). Sample homogenization with methanol-water (for AFs) and acetonitrile-water (for OTA) solutions were performed by Waring blender at high speed for $2 \mathrm{~min}$. Filtered and diluted extract was passed through AflaTest ${ }^{\circledR}$ and OchraTest ${ }^{\mathrm{TM}}$ IACs attached to a vacuum manifold at a flow rate of $2-3 \mathrm{ml} \mathrm{min}^{-1}$. The column was washed with $20 \mathrm{ml}(2 \times 10 \mathrm{ml})$ ultra-pure water and dried with air. Both $\mathrm{AF}_{\mathrm{s}}$ and OTA were eluted by passing $1 \mathrm{ml}$ methanol $(2 \times 0.5 \mathrm{ml})$ through the column. The eluate was evaporated to dryness at $45^{\circ} \mathrm{C}$ under $\mathrm{N}_{2}$ stream, and the residue was re-dissolved with $1 \mathrm{ml}$ of mobile phases.

\subsection{HPLC-FLD analysis}

Chromatographic analyses of AFs and OTA were carried out with a Shimadzu (Tokyo, Japan) HPLC system, consisting of an LC-20AD pump, a SIL-20AHT auto sampler, an RF-20AXL fluorescence detector (FLD), a CTO-20A thermostatic oven, a DGU-20A3 on-line degasser, and system controller (CBM-20Alite). Chromatographic separation was performed at $40{ }^{\circ} \mathrm{C}$ on Inertsil ODS-3 C column $(250 \times 4.6 \mathrm{~mm}, 5 \mu \mathrm{m})$. The mobile phase, consisting of wateracetonitrile-acetic acid $(6: 2: 3, \mathrm{v} / \mathrm{v} / \mathrm{v})$, was applied isocratically at flow rate $1 \mathrm{ml} \mathrm{min}^{-1}$ for 20 $\mathrm{min}$. Excitation and emission wavelengths for fluorescence detection were $360 \mathrm{~nm}$ and 440 $\mathrm{nm}$, respectively. The injection volume was $100 \mu \mathrm{l}$. For AFs post-column derivatization, a Kobra cell was used. In the derivatization process, $350 \mu \mathrm{l}$ nitric acid $\left(4 \mathrm{M}, \mathrm{HNO}_{3}\right)$ and 120 mg potassium bromide $(\mathrm{KBr})$ were mixed with $1000 \mathrm{ml}$ mobile phase for ionization.

For OTA analysis, the fluorescence detector was set at $333 \mathrm{~nm}$ for excitation and $460 \mathrm{~nm}$ for emission. The mobile phase (acetonitrile-water-acetic acid, 47:51:2, $\mathrm{v} / \mathrm{v} / \mathrm{v}$ ) was applied isocratically at a flow rate of $1 \mathrm{ml} \mathrm{min}$. An aliquot of $100 \mu 1$ was injected into the HPLC.

\subsection{Validation procedures}

Linearity, limits of detection (LOD) and quantification (LOQ), and method recovery were evaluated to confirm the method quality. The linearity of the method was estimated by injecting triplicate mycotoxins standard solutions at six different concentrations $\left(0.5-15 \mu \mathrm{g}^{-1}\right.$ for $\mathrm{AFB}_{1}$ and $\mathrm{AFG}_{1} ; 0.15-4.5 \mu \mathrm{g} \mathrm{l}^{-1}$ for $\mathrm{AFB}_{2}$ and $\left.\mathrm{AFG}_{2}\right)$. Linearity was calculated by linear regression analysis using the least squares method. Coefficient of determination $\left(R^{2}\right)$ value 
above 0.99 indicated the excellent analytical performance. Standard curves were used to calculate the concentration of the quality control and the unknown samples. The retention times of AFs were 9.6, 11.4, 12.7, and 15.3 min for $\mathrm{AFG}_{2}, \mathrm{AFG}_{1}, \mathrm{AFB}_{2}$, and $\mathrm{AFB}_{1}$, respectively, while that of OTA was $10.3 \mathrm{~min}$. The chromatograms of AFs and OTA standards are shown in Figure 2. The LODs and LOQs of $\mathrm{AF}_{\mathrm{S}}$ and OTA were estimated for a signal-to-noise ratio of 3 and 10, respectively. Method recovery was measured by the analysis of blank samples spiked with standard solutions at final concentrations of $5 \mu \mathrm{g} \mathrm{kg}^{-1}$ for $\mathrm{AFB}_{1}, \mathrm{AFG}_{1}$ and OTA, and $1.5 \mu \mathrm{g} \mathrm{kg}^{-1}$ for $\mathrm{AFB}_{2}$ and $\mathrm{AFG}_{2}$ in eight replicates. The spiked samples were analyzed as described previously and recovery was calculated as follows (Eq. 1):

Recovery $(\%)=($ measured content $/$ spiking level $) \times 100$

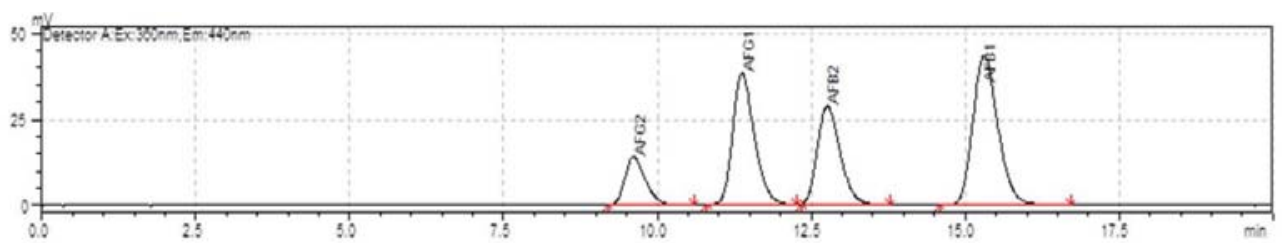

(a) $2.5 \mu \mathrm{g} \mathrm{H}^{-1} \mathrm{AFB}_{1}, 0.75 \mu \mathrm{g} \mathrm{H}^{-1} \mathrm{AFB}_{2}, 2.5 \mu \mathrm{g} \mathrm{H}^{-1} \mathrm{AFG}_{1}$ and $0.75 \mu \mathrm{g} \mathrm{H}^{-1} \mathrm{AFG}_{2}$

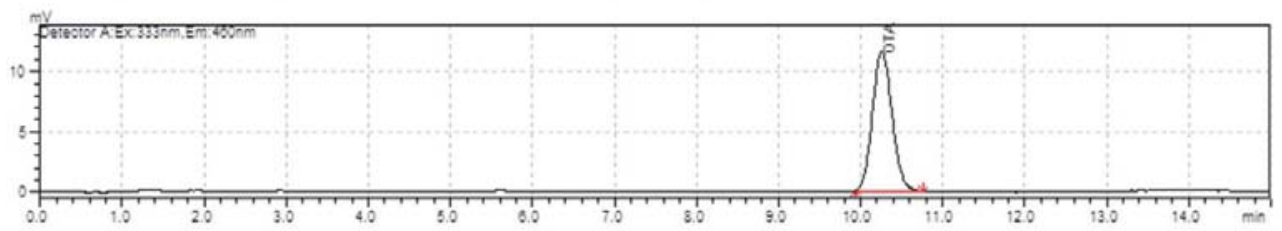

(b) $2.5 \mu \mathrm{g} \mathrm{H}^{-1}$ OTA

Fig. 2. Chromatograms of standard solutions showing $\mathrm{AF}_{\mathrm{S}}$ (a) and OTA (b)

\section{Results and discussion}

\subsection{Method performance}

The HPLC performance parameters (linearity, LODs, LOQs, and recovery) of $\mathrm{AFB}_{1}, \mathrm{AFG}_{1}$, $\mathrm{AFB}_{2}, \mathrm{AFG}_{2}$, and OTA are presented in Table 1 . The performances of the current analytical method were satisfactory for the purpose. The determination coefficients of calibration curves were 0.9985, 0.9991, 0.9994, 0.9991, and 0.9996 for $\mathrm{AFB}_{1}, \mathrm{AFG}_{1}, \mathrm{AFB}_{2}, \mathrm{AFG}_{2}$, and OTA, respectively. The LODs and LOQs of the analytical method ranged from 0.014 to $0.030 \mu \mathrm{g} \mathrm{kg}^{-1}$ and 0.045 to $0.098 \mu \mathrm{g} \mathrm{kg}^{-1}$ for $\mathrm{AF}_{\mathrm{S}}$ and OTA, respectively. The LOQ values of whole wheat samples for $\mathrm{AF}_{\mathrm{S}}$ and OTA were significantly lower than those of the EU MLs. Good recoveries (89.6-91.3\% for AFs and 96\% for OTA) were obtained, which conformed to the requirements of Commission Regulation (EC, 2006a). The regulation recommends recovery rate of $70-110 \%$ for both AFs and OTA for mass fraction of $1-10 \mu \mathrm{g} \mathrm{kg}^{-1}$.

\subsection{AFs content of whole wheat flour samples}

Results of both AFs and OTA are summarized in Table 2. 
Table 1. HPLC performance parameters for the analysis of $\mathrm{AF}_{\mathrm{S}}$ and OTA

\begin{tabular}{lcccccc}
\hline Mycotoxin & Range $\left(\mu \mathrm{g} \mathrm{l}^{-1}\right)$ & $\begin{array}{c}\text { Linearity } \\
\text { Linear regression equation }\end{array}$ & $R^{2}$ & $\begin{array}{c}\mathrm{LOD}^{\mathrm{a}} \\
\left(\mu \mathrm{gg}^{-1}\right)\end{array}$ & $\begin{array}{c}\mathrm{LOQ}^{\mathrm{b}} \\
\left(\mu \mathrm{kg}^{-1}\right)\end{array}$ & $\begin{array}{c}\text { Recovery } \\
(\%, n=8)\end{array}$ \\
\hline $\mathrm{AFB}_{1}$ & $0.5-15$ & $y=399625 x+21190$ & 0.9985 & 0.026 & 0.086 & 90.8 \\
$\mathrm{AFB}_{2}$ & $0.15-4.5$ & $y=884563 x-7526.6$ & 0.9991 & 0.014 & 0.045 & 89.6 \\
$\mathrm{AFG}_{1}$ & $0.5-15$ & $y=341664 x-12385$ & 0.9994 & 0.028 & 0.094 & 91.3 \\
$\mathrm{AFG}_{2}$ & $0.15-4.5$ & $y=361597 x+12944$ & 0.9991 & 0.021 & 0.068 & 90.4 \\
$\mathrm{OTA}$ & $0.5-15$ & $y=115494 x-6817$ & 0.9996 & 0.030 & 0.098 & 96.0 \\
\hline
\end{tabular}

$R^{2}$ : Coefficient of determination,

a : LOD, limit of detection of the chromatographic method $(\mathrm{S} / \mathrm{N}=3)$,

${ }^{\mathrm{b}}$ : LOQ, limit of quantification of the chromatographic method $(\mathrm{S} / \mathrm{N}=10)$

Table 2. Occurrence and concentrations of AFs and OTA in whole wheat flour samples

\begin{tabular}{|c|c|c|c|c|c|c|c|}
\hline $\begin{array}{l}\text { Sample } \\
\text { (n) }\end{array}$ & Parameter & $\mathrm{AFB}_{1}$ & $\mathrm{AFB}_{2}$ & $\mathrm{AFG}_{1}$ & $\mathrm{AFG}_{2}$ & Total $\mathrm{AF}_{\mathrm{S}}$ & OTA \\
\hline \multirow{5}{*}{$\begin{array}{l}\text { Wheat } \\
(141)\end{array}$} & $\begin{array}{l}\text { Positive sample }{ }^{\mathrm{a}}, \mathrm{n} \\
(\%)\end{array}$ & $3(2)$ & $1(0.7)$ & $\mathrm{ND}^{\mathrm{b}}$ & ND & $3(2)$ & $13(9.2)$ \\
\hline & $\begin{array}{l}\text { Number of samples above } \\
\text { EU limit }(\%)\end{array}$ & $0(0)$ & - & - & - & $0(0)$ & $0(0)$ \\
\hline & $\begin{array}{l}\text { Range } \\
\left(\min -\max , \mu \mathrm{g} \mathrm{kg}^{-1}\right)\end{array}$ & $0.21-0.35$ & 0.094 & - & - & $0.21-0.44$ & $0.1-3.2$ \\
\hline & $\begin{array}{l}\text { Mean of positive samples } \\
\left(\mu \mathrm{g} \mathrm{kg}^{-1}\right)\end{array}$ & 0.294 & 0.094 & $<$ LOD & $<$ LOD & 0.325 & 1.04 \\
\hline & Mean value $\left(\mu \mathrm{g} \mathrm{kg}^{-1}\right)$ & 0.019 & 0.008 & $<\mathrm{LOD}$ & $<\mathrm{LOD}$ & 0.020 & 0.11 \\
\hline
\end{tabular}

The $\mathrm{LOD}_{\mathrm{S}}$ for $\mathrm{AFB}_{1}, \mathrm{AFB}_{2}, \mathrm{AFG}_{1}, \mathrm{AFG}_{2}$, and OTA are $0.026,0.014,0.028,0.021$, and $0.03 \mu \mathrm{g} \mathrm{kg}^{-1}$, respectively.

${ }^{a}$ : Positive samples: mycotoxin level $>$ LOQ.

b: ND: none detected.

It is evident from the results that only 3 out of 141 whole wheat flour samples $(2 \%)$ were found contaminated with $\mathrm{AFB}_{1}$ having concentrations of $0.345,0.332$, and $0.205 \mu \mathrm{g} \mathrm{kg}^{-1}$. Besides, $0.094 \mu \mathrm{g} \mathrm{kg}^{-1} \mathrm{AFB}_{2}$ was detected in only one out of $3 \mathrm{AFB}_{1}$-contaminated samples. No groups of $G$ aflatoxins were found in any of the whole wheat flour samples analyzed. The concentrations of $\mathrm{AF}_{\mathrm{S}}$ positively identified in the samples were below the MLs $\left(\mathrm{AFB}_{1}\right.$ : $2 \mu \mathrm{g} \mathrm{kg}^{-1}$, total AFs: $4 \mu \mathrm{g} \mathrm{kg}^{-1}$ ) set by both EU regulations and Turkish Food Codex.

In a study related to the co-occurrence of $\mathrm{AF}_{\mathrm{S}}$ in cereal flours commercialized in Turkey, $\mathrm{AF}_{\mathrm{S}}$ were detected at levels equal to or above the $\mathrm{LOQ}_{\mathrm{S}}$ (KARA et al., 2015). In contrast to our results, Demirel and SARIOZLu (2014) stated that $\mathrm{AFB}_{1}, \mathrm{AFB}_{2}$ and $\mathrm{AFG}_{1}$ were was detected in 6 out of the 12 wheat flour samples in levels up to $6.6 \mu \mathrm{g} \mathrm{kg}^{-1}$ in Turkey. In another study, $45 \%$ of wheat flour samples were contaminated with $\mathrm{AF}_{\mathrm{S}}$ at an average level of $0.79 \mu \mathrm{g} \mathrm{kg}^{-1}$. However, only $2 \%$ of the samples exceeded the ML of total $\mathrm{AF}_{\mathrm{S}}$ (AYDIN et al., 2008). In a study by GirAY et al. (2007), $\mathrm{AFB}_{1}, \mathrm{AFB}_{2}, \mathrm{AFG}_{1}$, and $\mathrm{AFG}_{2}$ were found in $42 \%, 12 \%, 37 \%$, and $12 \%$ of the wheat samples grown in Turkey, respectively. In another study in Turkey, $59 \%$ of the samples were contaminated with $\mathrm{AF}_{\mathrm{S}}$, but all values were under the MLs for the total $\mathrm{AF}_{\mathrm{S}}$ (BAYDAR et al., 2005). 
In addition to the results obtained in Turkey, other studies from several different countries showed varied results for the $\mathrm{AF}_{\mathrm{S}}$ contamination in wheat products. In Pakistan, 20\% of 95 wheat samples were found to contain AFs up to $15.5 \mu \mathrm{g} \mathrm{kg}^{-1}$ (LUTFUllaH \& HusSAIN, 2012). In a similar study, two out of nine cereal samples from Egypt were contaminated with $\mathrm{AF}_{\mathrm{S}}$ at values of 0.47 and $0.29 \mu \mathrm{g} \mathrm{kg}^{-1}$ (ABDEL-AzEem et al., 2015). Additionally, NAmjoo and coworkers (2016) indicated that 10 out of 34 wheat samples were contaminated with $\mathrm{AF}_{\mathrm{S}}$ but none was found above the MLs in Iran $\left(15 \mu \mathrm{g} \mathrm{kg}^{-1}\right)$.

\subsection{OTA content of whole wheat flour samples}

As can be seen in Table 2, thirteen samples (9.2\%) were contained with OTA ranging 0.1-3.2 $\mu \mathrm{g} \mathrm{kg}{ }^{-1}$. None of them overpassed the MLs of $5 \mu \mathrm{g} \mathrm{kg}^{-1}$ set by Turkish regulations and European Commission for unprocessed cereals.

Wheats are more susceptible to OTA attacks than that of $\mathrm{AF}_{\mathrm{S}}$. In contrast to our study, higher mean levels of OTA were found by KARA et al. (2015) $(26.7 \%, n=60)$, DEMIREL and SARIOZLU (2014) (91.7\%, n=12), and AYDIN and co-workers (2008) (81\%, n=100). However, our findings show similarity with the range of OTA mean level observed by DEMIREL and SARIOZLU (2014) (0.8-3 $\left.\mu \mathrm{g} \mathrm{kg}^{-1}\right)$. In another study, 50 wheat samples were collected from the northern states of India for investigation of OTA levels. They found that $29(58 \%)$ wheat samples were contaminated with OTA ranging from 1.36 to $21.17 \mu \mathrm{g} \mathrm{kg}^{-1}$ (KumAR et al., 2012). Differences in the OTA level of wheat samples may be due to the origin, year of harvest, and climate conditions (IQBAL et al., 2014). According to the exposure assessment data in European Union countries, cereal-based products finish in "first place" with OTA exposure of about 50\% (EC, 2002). Contamination of wheat grains with the toxigenic $P$. verrucosum strains may occur during harvesting, drying, and storage operations. Although, there are many factors affecting fungal development and mycotoxin formation in the grain. Climate conditions are another important factor affecting the formation of fungal colonies and mycotoxin. The prevalent climate conditions necessary for the development of ochratoxigenic moulds in Turkey make the possibility of OTA contamination during the preharvest and post-harvest stages of the grain (GOLGE \& KABAK, 2016) a clear factor in these findings.

\section{Conclusions}

This study is of great importance in that it was carried out on a large number of wheat samples collected from different regions of Turkey. AFs and OTA contamination levels in wheat samples were detected as $2 \%$ and $9.2 \%$, respectively. The contamination levels should be monitored routinely to guarantee food safety. It is also recommended that good agricultural practices and circumspect production techniques should be combined with the vigilant monitoring of moisture content, especially during storage of agricultural products.

The levels of $\mathrm{AF}_{\mathrm{S}}$ and OTA contamination varied based on the harvest year, region, and climatic conditions. Since wheat-based products form major parts of daily nutrition for a majority of the Turkish population, the mycotoxin contamination detected in wheat samples has been a considerable problem for the Turkish nation, despite their low levels.

The authors would like to thank the Scientific Research Council of Hitit University (Project No: MUH19003.14.002) for the financial support of this work. 


\section{References}

Abdel-Azeem, S.M., Diab, M.A. \& El-Shahat, M.F. (2015): Ultra-high-pressure liquid chromatography-solidphase clean-up for determining aflatoxins in Egyptian food commodities. J. Food Compos. Anal., 44, 18-24.

Aydin, A., Gunsen, U. \& Demirel, S. (2008): Total aflatoxin, aflatoxin B1 and ochratoxin A levels in Turkish wheat flour. J. Food Drug Anal., 16(2), 7.

Baydar, T., Engin, A.B., Girgin, G., Aydin, S. \& Sahin, G. (2005): Aflatoxin and ochratoxin in various types of commonly consumed retail ground samples in Ankara, Turkey. Ann Agr. Env. Med., 12, 193-197.

Birzele, B., Prange, A. \& Kramer, J. (2000): Deoxynivalenol and ochratoxin A in German wheat and changes of level in relation to storage parameters. Food Addit. Contam., 17(12), 1027-1035.

Demirel, R. \& SAriozlu, N.Y. (2014): Mycotoxigenic moulds and mycotoxins in flours consumed in Turkey. J. Sci. Food Agr., 94, 1577-1584.

EC (2006a): Commission Regulation (EC) No 401/2006 of February 2006 laying down methods of sampling and analysis for the official control of the levels of mycotoxins in foodstuffs. O.J. of EU L 70, 12-34.

EC (2006b): Commission Regulation (EC) No 1881/2006 of 19 December 2006 setting maximum levels for certain contaminants in foodstuffs. O.J. of EU L 364, 5-24.

EC (2002): Report of experts participating in task 3.2.7. Assessment of dietary intake of ochratoxin A by the population of EU member states. Directorate-General Health and Consume Protection.

EFSA (2006): Opinion of the Scientific Panel on contaminants in the food chain [CONTAM] related to ochratoxin A in food. EFSA J., 4(6), 365.

FAO (2018): FAO (Food and Agricultural Organization of the United Nations) Cereal Supply and Demand Brief

Giray, B., Girgin, G., Engin, A.B., Aydin, S. \& SAhin, G. (2007): Aflatoxin levels in wheat samples consumed in some regions of Turkey. Food Control, 18(1), 23-29.

GolgE, O. \& KABAK, B. (2016): First report: Exposure estimates to ochratoxin A through wheat bread and rice intake in Turkey. J. Cereal Sci., 69, 213-217.

Hajok, I., Kowalska, A., Piekut, A. \& Drabek, M.C. (2019): A risk assessment of dietary exposure to ochratoxin A for the Polish population. Food Chem., 284, 264-269.

IARC (1993): Some naturally occurring substances: Food items and constituents, heterocyclic aromatic amines and mycotoxins. IARC Monographs on the Evaluation of the Carcinogenic Risk of Chemicals to Humans, 56.

IQBAL, S.Z., RABBANI, T., Asi, M.R. \& JinAP, S. (2014): Assessment of aflatoxins, ochratoxin A and zearalenone in breakfast cereals. Food Chem., 157, 257-262.

Joubrane, K., Khoury, A.E., Lteif, R., Rizk, T., Kallasy, M., Hilan, C. \& Maroun, R. (2011): Occurrence of aflatoxin B1 and ochratoxin A in Lebanese cultivated wheat. Mycotoxin Res., 27, 249-257.

Kara, G.N., OzBey, F. \& KabaK, B. (2015): Co-occurrence of aflatoxins and ochratoxin A in cereal flours commercialised in Turkey. Food Control, 54, 275-281.

Kumar, R., Ansari, K.M., Saxena, N., Dwivedi, P.D., Jain, S.K. \& Das, M. (2012): Detection of ochratoxin A in wheat samples in different regions of India. Food Control, 26(1), 63-67.

Lutfullah, G. \& Hussain, A. (2012): Studies on contamination level of aflatoxins in some cereals and beans of Pakistan. Food Control, 23(1), 32-36.

Makun, H.A., Anjorin, S.T., Moronfoye, B., Adejo, F.O., Afolabi, O.A. \& Fagbayibo, G. (2010): Fungal and aflatoxin contamination of some human food commodities in Nigeria. Afr. J. Food Sci., 4(4), 127-135.

Namjoo, M., Salamat, F., Rajabli, N., Hajihoseeini, R., Niknejad, F., Kohsar, F. \& Joshaghani, H. (2016): Quantitative determination of aflatoxin by high performance liquid chromatography in wheat silos in Golestan Province, North of Iran. Iran. J. Public Health, 45, 905-910.

TUIK (2018): TUIK (Turkish Statistical Institute). The summary of agricultural statistics.

Vidal, A., Marin, S., Ramos, A.J., Cano-Sancho, G. \& Sanchis, V. (2013): Determination of aflatoxins, deoxynivalenol, ochratoxin A and zearalenone in wheat and oat-based bran supplements sold in the Spanish market. Food Chem. Toxicol., 53, 133-138.

Zebiri, S., Mokrane, S., Verheecke-Vaessen, C., Choque, E., Reghioui, H., ... \& Riba, A. (2019): Occurrence of ochratoxin A in Algerian wheat and its milling derivatives. Toxin Rev., 38(3), 206-211.

ZhaO, Y., WANG, Q., HuANG, J., MA, L., CHEN, Z. \& WANG, F. (2018): Aflatoxin B1 and sterigmatocystin in wheat and wheat products from supermarkets in China. Food Addit. Contam. B, 11(1), 9-14. 